\title{
Article \\ Sediment Characteristics and Intertidal Beach Slopes along the Jiangsu Coast, China
}

\author{
Yu Kuai ${ }^{1, *(\mathbb{D})}$, Jianfeng Tao ${ }^{2, *(\mathbb{D})}$, Zaiyang Zhou ${ }^{1,3}{ }^{(\mathbb{C}}$, Stefan Aarninkhof ${ }^{1}$ and Zheng Bing Wang ${ }^{1,4}$ \\ 1 Faculty of Civil Engineering and Geosciences, Delft University of Technology, \\ 2628 CN Delft, The Netherlands; zhouzaiyang@126.com (Z.Z.); S.G.J.Aarninkhof@tudelft.nl (S.A.); \\ Zheng.Wang@deltares.nl (Z.B.W.) \\ 2 College of Harbor, Coastal and Offshore Engineering, Hohai University, Nanjing 210098, China \\ 3 State Key Laboratory of Estuarine and Coastal Research, East China Normal University, \\ Shanghai 200062, China \\ 4 Marine and Coastal Systems Department, Deltares, 2600 MH Delft, The Netherlands \\ * Correspondence: y.kuai@tudelft.nl (Y.K.); aoetao@hhu.edu.cn (J.T.)
}

Citation: Kuai, Y.; Tao, J.; Zhou, Z.; Aarninkhof, S.; Wang, Z.B. Sediment Characteristics and Intertidal Beach Slopes along the Jiangsu Coast, China. J. Mar. Sci. Eng. 2021, 9, 347. https://doi.org/10.3390/jmse9030347

Academic Editor: Matteo Vacchi

Received: 8 March 2021

Accepted: 19 March 2021

Published: 22 March 2021

Publisher's Note: MDPI stays neutral with regard to jurisdictional claims in published maps and institutional affiliations.

Copyright: (c) 2021 by the authors. Licensee MDPI, Basel, Switzerland. This article is an open access article distributed under the terms and conditions of the Creative Commons Attribution (CC BY) license (https:// creativecommons.org/licenses/by/ $4.0 /)$.

\begin{abstract}
Tidal flats play an important role in promoting coastal biodiversity, defense against flooding, land reclamation and recreation. Many coastal tidal flats, especially the tide-dominant ones, are muddy. However, the number of studies on the profile shape and surficial sediment distribution of muddy tidal flats is small compared to sandy beaches. Based on high spatial-resolution measurements along the tide-dominant Jiangsu Coast, China, we analyzed the morphology and sediment characteristics of the unvegetated intertidal flats along the Jiangsu Coast. The Jiangsu Coast can be divided into an eroding northern part (north coast) and an accreting southern part (south coast). The beach slope of the north coast shows a southward flattening trend, apart from some outliers related to rocky parts of the coastline. We found alternating very fine and coarse sediment (depending on the local clay content) for different locations along the north coast, which can be explained from consolidation and armoring-induced erosion resistance. In the south coast, we found gradual coarsening of bed surface sediment and gradual flattening of beach slopes to the south. This seemingly unexpected pattern is explained by the flood-dominant current causing landward sediment transport, larger tidal range in the south part, sheltering effect of the Radial Sand Ridges, and contribution of different sediment sources, viz. the Abandoned Yellow River Delta and the Radial Sand Ridges. In the cross-shore direction, the sediment grain size decreases landward. Waves are only of secondary importance for the sediment dynamics at the unvegetated tidal flats along the Jiangsu Coast.
\end{abstract}

Keywords: intertidal beach; beach slope; surficial sediment grain-size; human intervention; Jiangsu Coast

\section{Introduction}

Located at the boundary between land and sea, tidal flats are under the joint control of both terrestrial and marine processes, while they play a vitally important role in promoting coastal biodiversity, protecting coastal regions from flooding, and providing potential land resources and recreation. Nowadays, in the progress of coastal resource development, many human activities (e.g., ports construction, reclamation) are conducted on tidal flats, like the Tongzhou Bay port on the Jiangsu Coast, China [1] and the Maasvlakte reclamation in the Netherlands [2]. Therefore, tidal flat evolution has been a key research topic in the field of coastal engineering.

Many studies have been carried out on the characteristics of sandy, wave-dominated beach profiles [3-6]. Sandy beaches with coarse materials tend to be steeper [7,8]. Coarser sands have larger angle of repose than finer ones. In addition, due to their higher permeability and roughness, coarser materials tend to be more stable in dynamic conditions [8]. However, because of difficulties in field observation, the number of studies on the profile 
shape and sediment distribution of the muddy and silt-muddy tidal flats is far less than for sandy beaches. It is found that accreting tidal flats tend to have a convex-up shore-normal profile, while eroding tidal flats tend to have a concave-up one $[9,10]$. The intertidal flats in muddy environments are more convex-up than those in sandy environments [11].

Silt-muddy tidal flats are shallow areas characterized by fine cohesive sediment including clay $(<0.004 \mathrm{~mm})$, silt $(0.004-0.062 \mathrm{~mm})$ and very fine sand $(0.062-0.125 \mathrm{~mm})$ supplied from adjacent rivers, estuaries and coasts. They are found worldwide under a variety of climatic, hydrodynamic and sedimentological conditions, such as the East Coast of China [12], the Northwest Coast of America [13], the Severn Estuary of the UK [14] and the Wadden Sea in the Netherlands [15]. Based on the different dynamic conditions and terrains, silt-muddy tidal flats can be divided into open coast, embayment and estuarine tidal flats, among which the open coast tidal flat can be well developed because of complex dynamics and less restrictions for sediments transport routes. Figure 1 shows a characteristic cross-shore sediment zonation pattern for a well-developed siltmuddy tidal flat.

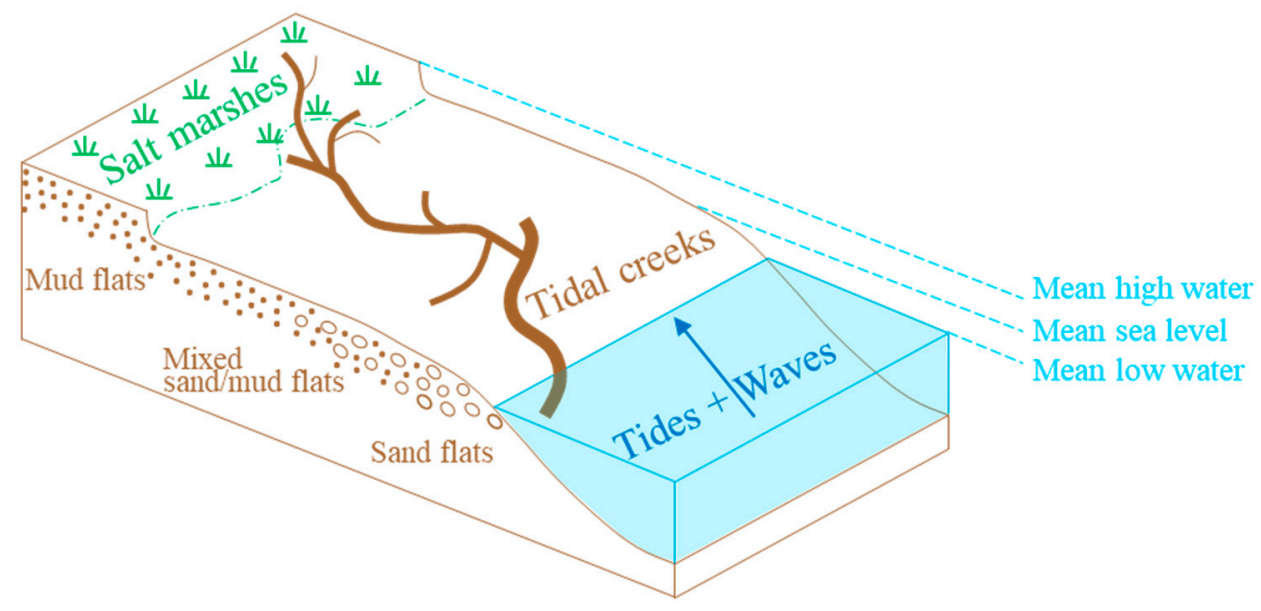

Figure 1. A profile view of sediment zonation (modified from [11]).

Although silt-muddy tidal flats exist worldwide broadly, they are of different characteristics for several reasons. First of all, the sediment transport itself is a complex and multi-dimensional process that closely relates to the interactions involving various external forcing agents (e.g., tide, wave, wind and storm surge) [16,17]. In addition, the difference in sediment compositions (e.g., clay, silt and very fine sand) and biological activities have apparent impacts on the processes like sediments erosion, mixing, deposition and bed consolidation [18]. Furthermore, changing environments (e.g., sea level rise, sediment supply) and human activities in different regions can also lead to different tidal flat morphologies [19]. Thorough understanding of nearshore morphodynamic processes including the link between hydrodynamic forcing, surficial sediment distribution and beach profile change is of crucial importance for the assessment of coastal safety and natural values, as well as the impact of human interventions in the coastal zone.

Jiangsu Coast, China, is such a typical open coast with extended silty-muddy tidal flats. It represents great economic and environmental value for the country; it not only provides shelters for the littoral flora and fauna, land resources for agriculture and aquaculture, but also protects the safety of coastal cities. The goal of this study is to increase our insight in the morphological characteristics of the unvegetated intertidal flats along the Jiangsu Coast. On the basis of high-resolution bed surface sediment grain size and cross-shore profile elevation data from a large-scale coastal investigation, we analyzed the beach profile evolution and sediment distribution patterns along this coast. 


\section{Area Description}

The Jiangsu Coast (Figure 2c) is situated between the Yangtze River and the Xiuzhen River Estuary [20]. Tidal flats along the Jiangsu Coastline are characterized by (1) its large width (with a mean width of $8 \mathrm{~km}$ ), (2) abundant sediment supply from the two large rivers (from the Yangtze River during the end of the late Pleistocene and from the Yellow River from 1128-1855 AD), and (3) silt dominant sediments [21]. It has been regarded generally as a typical example of open coast tidal flats [22]. From the embankment to mean low water, four distinctive zones can normally be found, which are grass flat (freshwater or brackish water wetland), Suaeda salsa flat (saltmarsh) and mud flat and silt or sand flat, respectively [21].

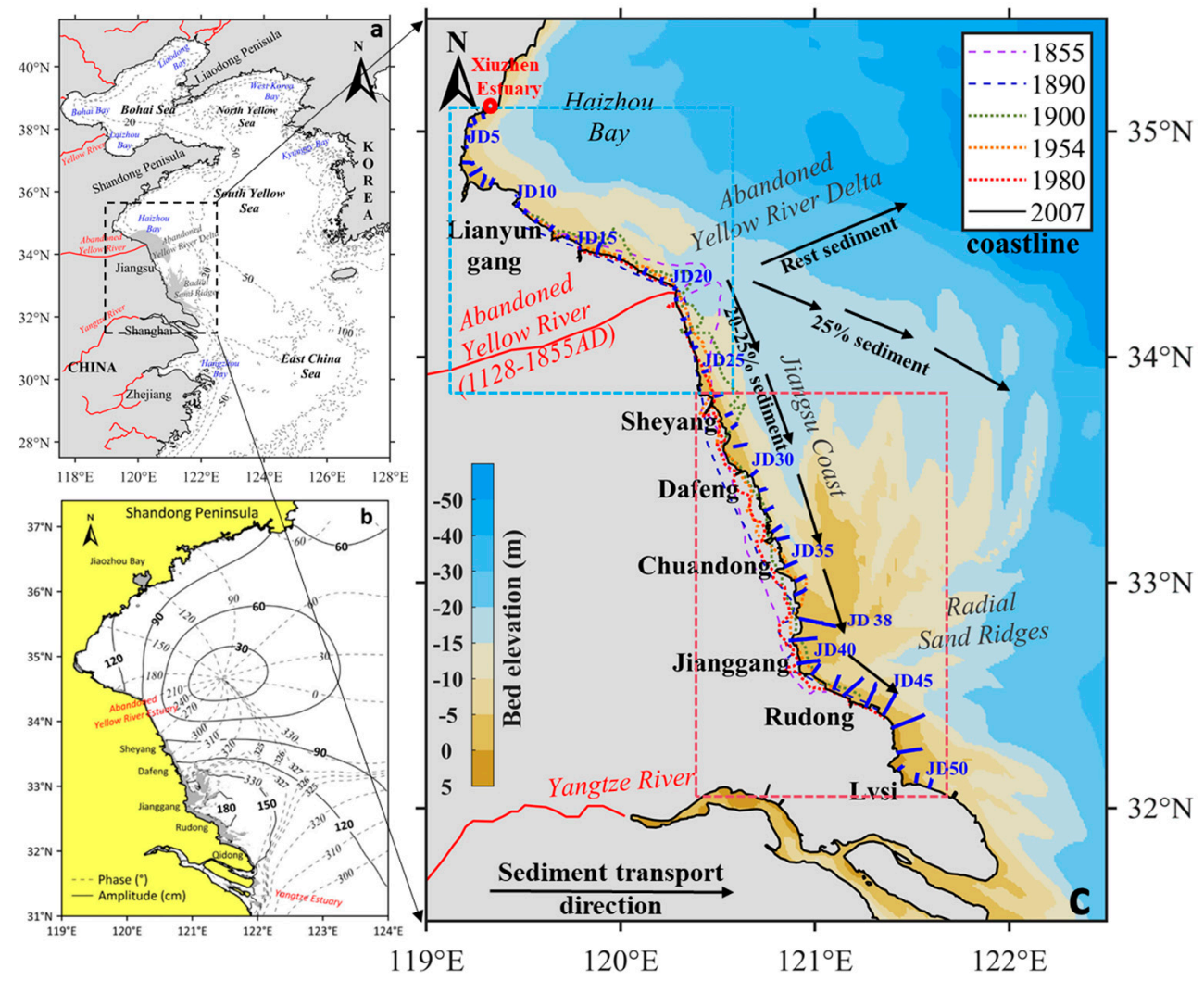

Figure 2. Map of the Bohai Sea, Yellow Sea and East China Sea (a). Subplot (b) shows the co-tidal charts of the M2 constituent for the southern Yellow Sea. Amplitude is shown in cm, and phase in degrees (from [23]). Subplot (c) indicates the Jiangsu Coastline evolution from 1855 to 2007, transport pattern of the sediment eroded from the Abandoned Yellow River Delta and the location of measured profiles. The locations of the Abandoned Yellow River Delta and the Radial Sand Ridges are labelled in (a), and the historical shoreline location in (c) is collected from [24], in which there is a detailed description of the shoreline data.

Two distinct geomorphological units can be recognized in the north and south parts of the Jiangsu Coast, respectively, i.e., the Abandoned Yellow River Delta (AYRD) and the fan-shaped Radial Sand Ridges (RSRs) [25-27]. During 1128-1855 AD, the Yellow River flowed into the South Yellow Sea at the north part of the Jiangsu Coast causing abundant fine sediment supply into the coastal areas, and gradually forming the (now) Abandoned Yellow River Delta [25]. The paleo-Yangtze River also brought a large amount of sandy sediment to the RSRs, during the end of the late Pleistocene [28]. These two large sediment sources led to a rapid tidal-flat formation. After 1855, The Yellow River shifted its lower reach to the Bohai Sea [29]. As the Yangtze River Estuary moved southward as well [25]. The suspended sediments in the coastal areas are since then mainly generated by bed erosion, instead of fluvial supply, and the whole coastal areas can be treated as 
a quasi-enclosed sediment system [30,31]. As a result, severe coastal erosion took place around the AYRD due to the cutoff of sediment supply (Figure 2c).

After the 1970s, some shoreline protection projects were built at the AYRD, which decreased the shoreline regression rate. While the shallow part of the coastal profile remained in place, erosion of the deeper part continued resulting in a steepening of the cross-shore slope. Sheltered by enormous offshore ridges and fed by sediments supply derived from the eroding AYRD and these ridges, the coast between Sheyang and Lvsi is still accreting, most notably at the supratidal flats. The mudflats from Sheyang to Jianggang are the widest and fastest accretionary mudflats in China [32]. Meanwhile, due to decreasing sediment supply from the AYRD and erosion of the outer edges of the radial sand ridges (thus decreasing the length of sheltered coastline), the eroding section near Sheyang is gradually expanding southwards [27].

The semi-diurnal tide is of major importance for the tidal flats along the Jiangsu Coast. The tidal wave first enters the southern Yellow Sea and part of it is reflected by the Shandong Peninsula, forming an anticlockwise rotational tidal wave system. The rotational wave and the progressive wave from the southern Yellow Sea converge near Jianggang (Figure $2 b$ ). The convergence of these two tidal waves leads to the formation of an approximately standing tidal wave and the radial tidal current field in this area [23,33,34]. The mean tidal range along the Jiangsu Coast is about $2-4 \mathrm{~m}$ (see Figure 3, [22]). The tide there is flood dominant, which is of great importance to net sediment transport [32,35].

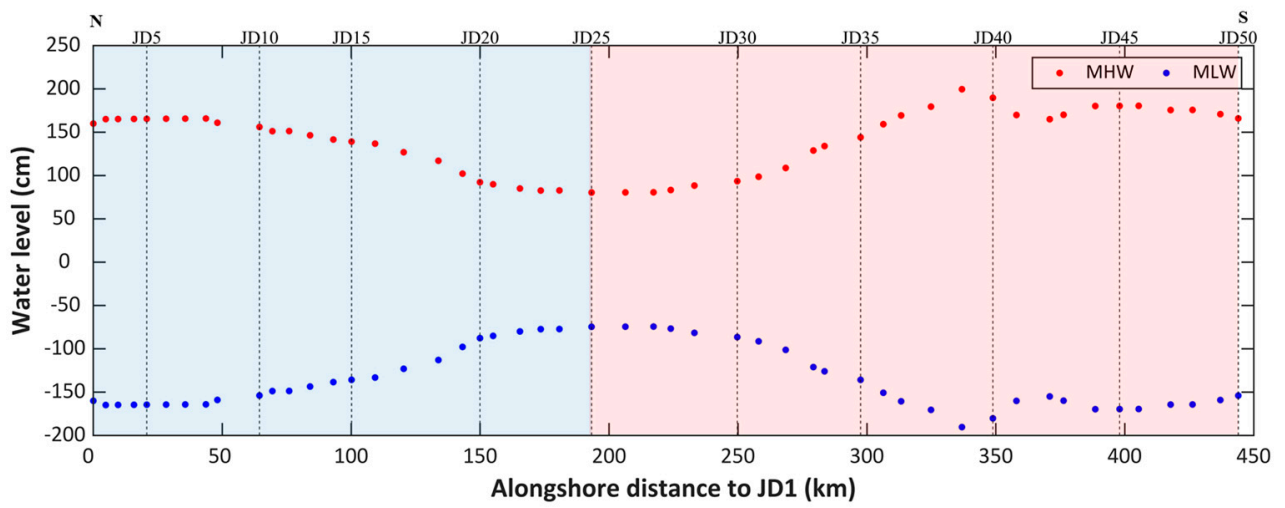

Figure 3. Interpolated mean high water (MHW) and mean low water (MLW) at each profile (the vertical dash lines indicate the location of every fifth profile; $\mathrm{N}$ denotes North and $\mathrm{S}$ denotes South and these are the same for the following figures).

The waves along the Jiangsu coastline are influenced primarily by the monsoon climate, characterized by a mixture of swells and locally generated wind waves with the latter being dominant. Waves from the north prevail in this region over the year and the probability of wave height smaller than $1 \mathrm{~m}$ is about $85 \%$ [22]. Due to the wave energy attenuation on the wide and shallow tidal flats, the effect of wave action on changing the coastal morphology is much weaker than the tidal action [22,35].

Classified by the mean grain size $\left(M_{Z}\right)$ and the sand $\left(-1 \sim 4 \Phi, \Phi=-\log _{2} d, d\right.$ is grain size in $\mathrm{mm})$, silt $(4 \sim 8 \Phi)$, and clay $(>8 \Phi)$ proportion, the tidal flat sediments at the Jiangsu Coast are mainly composed of five types of sediment, named fine sand $\left(M_{Z} 2-4 \Phi\right.$, sand $70-90 \%)$, sandy silt $\left(M_{Z} 3-5 \Phi\right.$, sand $30-40 \%$, silt $>50 \%$, clay $\left.<10 \%\right)$, silt $\left(M_{Z} 5-6 \Phi\right.$, sand $15-20 \%$, silt $65-75 \%$, clay $<10 \%)$, clayed silt $\left(M_{Z} 5.5-6.5 \Phi\right.$, sand $5-10 \%$, silt $>60 \%$, clay $20-25 \%$ ) and clay $\left(M_{Z} 7.5-8 \Phi\right.$, sand $<17 \%$, silt $20-25 \%$, clay $\left.45-70 \%\right)$. The distribution of surface sediment on intertidal flats shows a seaward coarsening trend [21].

\section{Material and Method}

\subsection{Data Source}

Data of cross-shore beach profile bathymetry and grain size distribution of sediment samples are from a comprehensive field survey on coastal zone of Jiangsu province, which 
has been reported in [36]. To the authors' knowledge, this is the latest field survey dataset with such a large spatial scale on the Jiangsu Coast. The large-scale investigations were performed between 2006 and 2008. Fifty cross-shore profiles starting from Xiuzhen estuary to Lvsi (Figure 2c) were defined along the Jiangsu Coast. The bed elevation was measured along these 50 profiles and 173 bed surface sediment samples were taken along only 36 of these profiles. For the bed elevation, the intertidal part was measured in 2007 by Real Time Kinematic (RTK) instrument (with a cross-shore interval of $\sim 70 \mathrm{~m}$ ), and subtidal part was measured in 2008 by vessel measurement (with a cross-shore interval of $\sim 10 \mathrm{~m}$ ). The samples were collected from the same layer (approximately the top $10 \mathrm{~cm}$ of the bottom) in 2006 and 2007, and only the top (1-2 cm) of the samples are adopted for sediment gradation analysis. For the sediment samples on the same profile, the distance between adjacent sample points is around $500 \mathrm{~m}$. Because the south part of the Jiangsu Coast has wider intertidal flats than the north part, more sample points were taken on the southern profiles. In addition, the Landsat 7 ETM satellite images were used to check for detailed information, such as locations of the tidal creeks and human interventions in the past 20 years. The satellite images are downloaded from the United States Geographical Survey website (USGS, http:/ / www.usgs.gov (accessed on 14 January 2020)).

\subsection{Data Processing}

In Figure 2c, two dash line rectangles were marked to divide the whole coastline into two parts, based on the shoreline evolution condition (erosion or accretion). The blue one (JD1-25, hereafter referred to as north part/north coast) contains the Haizhou Bay and the AYRD. Haizhou Bay is the only zone of the Jiangsu Coast having rock coast with typical sandy sediment. The coastline around the AYRD is under severe erosion since 1855 when the Yellow River switched its course. During the large-scale investigation (2006-2008), the shoreline erosion in this part was already at a much slower rate. The red one (JD26-50, hereafter referred to as south part/south coast) is under continuous accretion. This part is the most typical silty beach along the Jiangsu Coast. The alongshore distance is measured the between the landward ends of the adjacent profiles.

In order to compare the profile shapes, the intertidal flat slope was determined. We estimate the intertidal flat slope (slope $=\tan \alpha$, see Figure 4 ) from the width of the intertidal beach, as determined from the locations of the mean high water (MHW) and mean low water (MLW) beach contours. The MHW and MLW levels are determined from the historical Yellow Sea mean tidal range distribution data after [22], assuming Mean Sea Level (MSL) is half-way between MHW and MLW (see Figure 3). The elevations thus obtained can be used to determine the MHW and MLW locations at each profile.

This approach is obscured by potential presence of old/new dykes at the shoreward end of the profile and presence of tidal channels at the seaward end of the profile, which hamper consistent identification of the MHW and MLW contour locations. A systematic approach was followed to overcome these difficulties at either end of the beach profile, in order to enable quantitative beach slope estimates along the Jiangsu Coast. This approach (Baseline Method) is explained here:

At the shoreward end of the profile, old dykes and newly built dykes are occasionally located below MHW. Instead of calculating the intertidal beach slope from the MHW level, at influenced profiles (e.g., 17, 33, and 35) we choose the most seaward dyke toe and associated beach elevation to be the start point (see Figure 4).

At the seaward end of the profile, as we link the satellite images (Figure 5) to the measured profile data (Figure 6), we can find that in the region of the RSRs, the intertidal flat is cut through by tidal creeks of different sizes at many places, and these tidal creeks change their locations continuously. Here, we took profile JD 38 (see Figure 2c) for example. As we see in Figure 5, the profile JD38 shows strong fluctuations. It is not easy to define the seaward end point for intertidal beach slope calculation on this profile, because there are several positions of which the elevation is equal to MLW. For the previous approach, we simply took the most seaward one as the end point, as the blue arrow shows in Figure 5. 
However, as some tidal creeks could be rather wide and deep, we cannot take the whole profile as a continuous one, because this could make the beach slope definition criterion differ among profiles. Hence, for these profiles (e.g., 38, 39, 43 50) cut through by a large (wider than $100 \mathrm{~m}$ or deeper than $1 \mathrm{~m}$ ) tidal creek, we defined the end point as the landward bank (the point where cross-shore slope changes abruptly) of the tidal creek, as the red arrow shows in Figure 5.

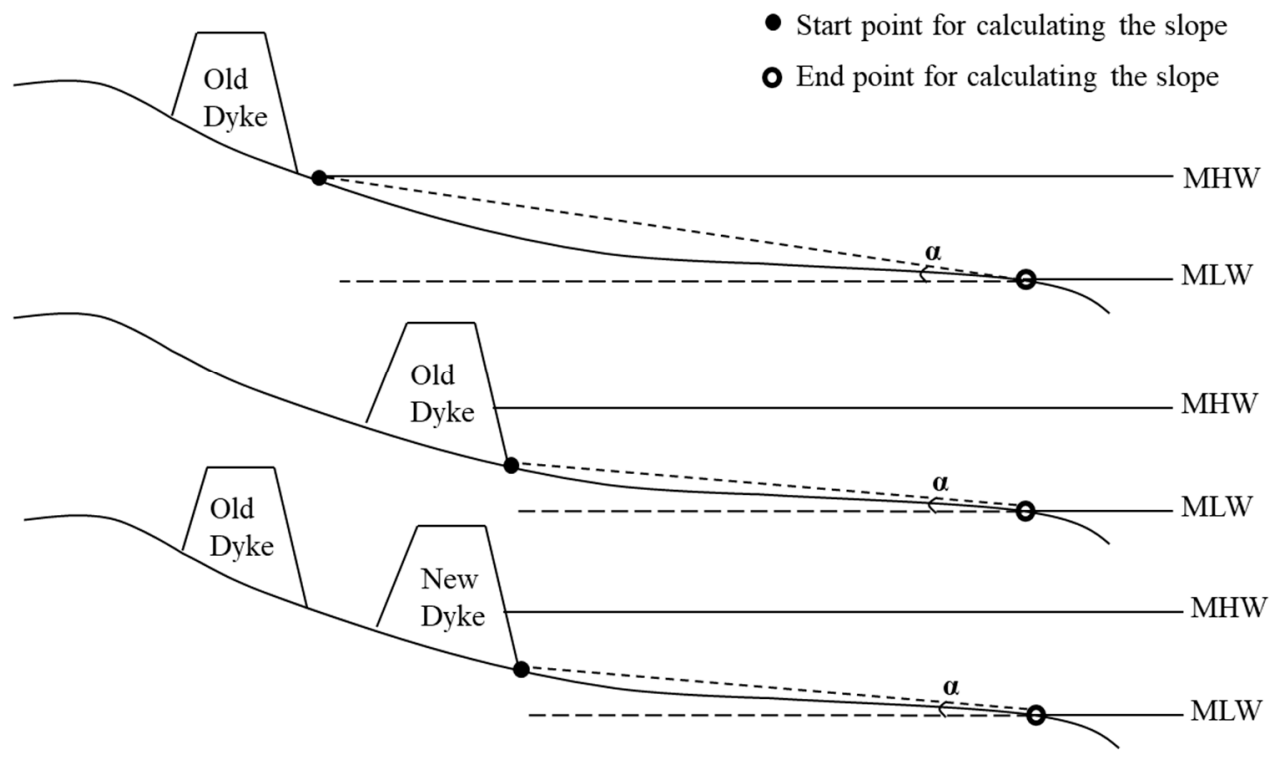

Figure 4. Scheme of calculating the intertidal flat slope.
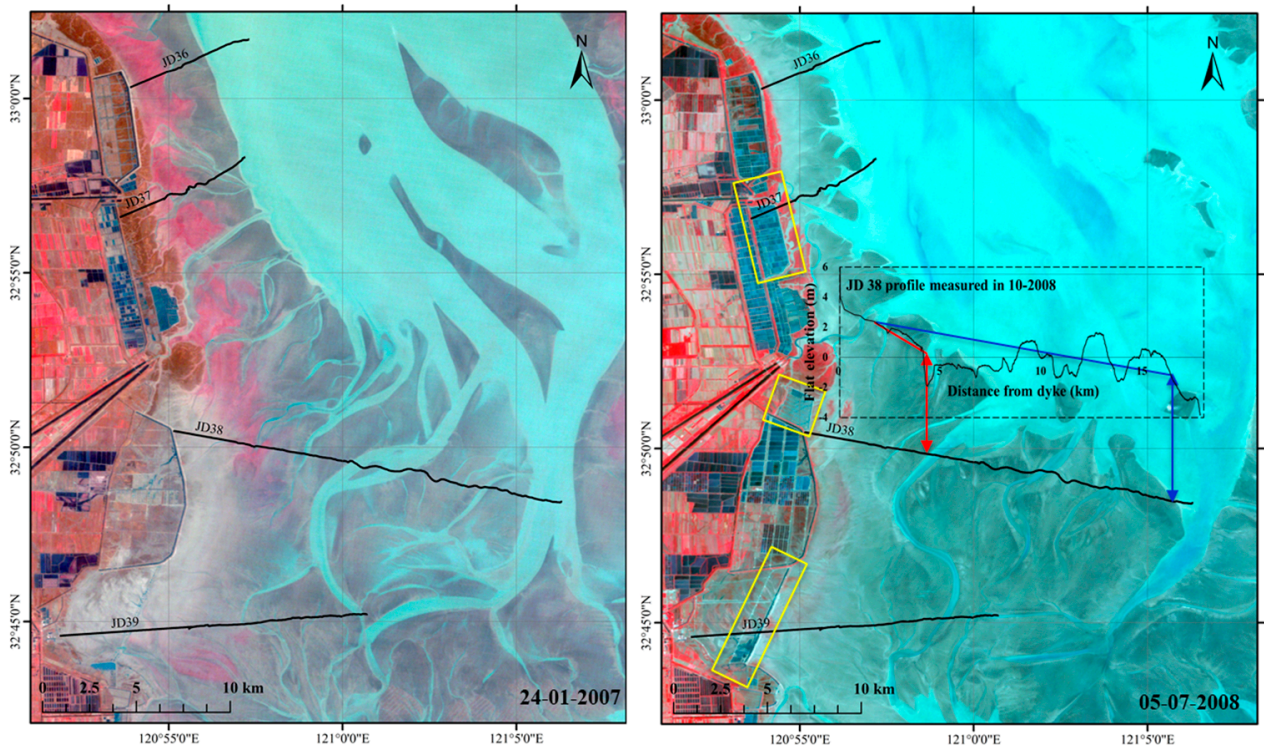

Figure 5. Satellite image of the JD 36 to 39 from Landsat 7 ETM on 24 January 2007 (left panel) and 5 July 2008 (right panel). The yellow box indicates the human interventions taking place between these two image times. The dash black box indicates the measured profile JD38 in October 2008, and the red and blue lines in the dash box are associated with two beach slope calculation methods. 

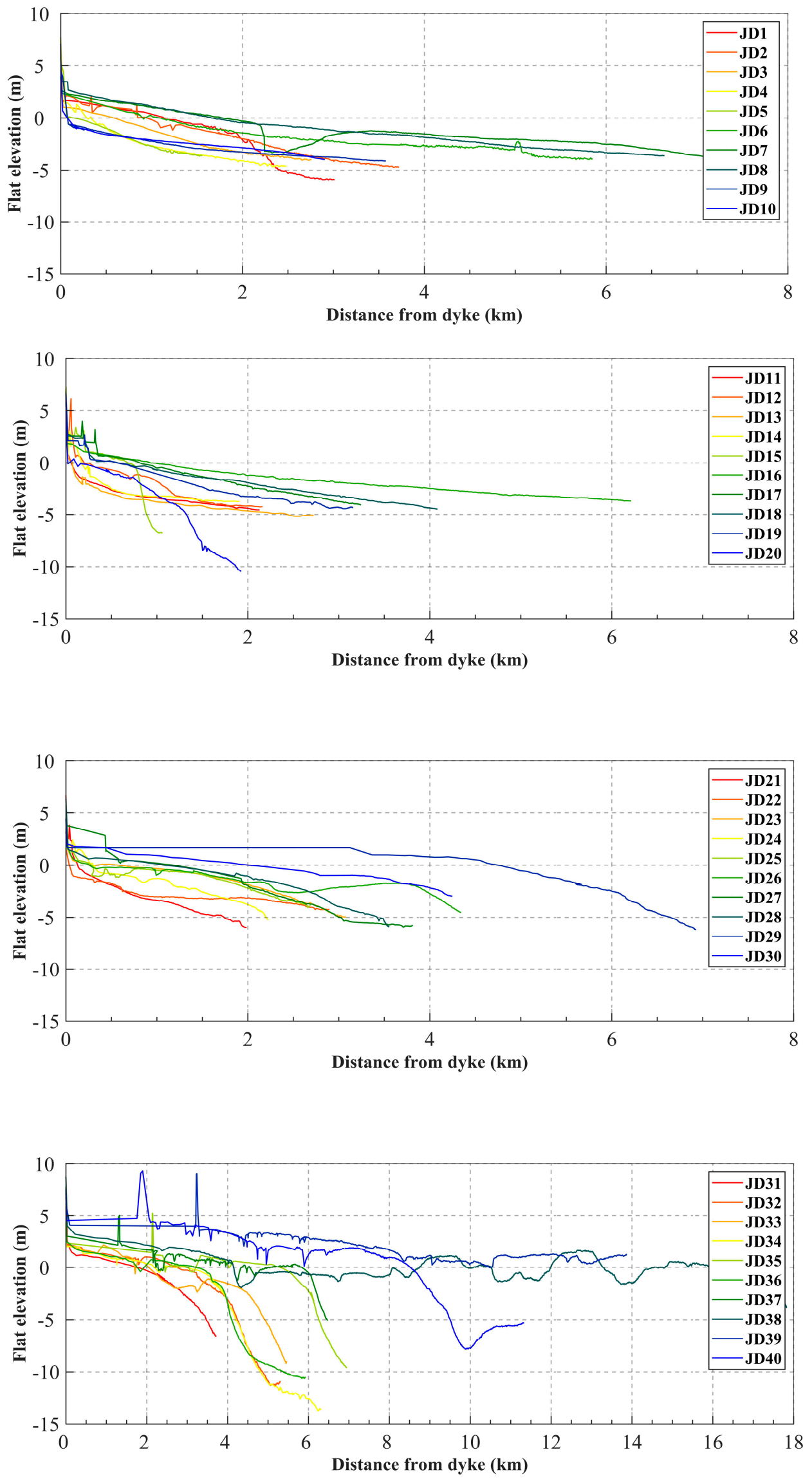

Figure 6. Cont. 


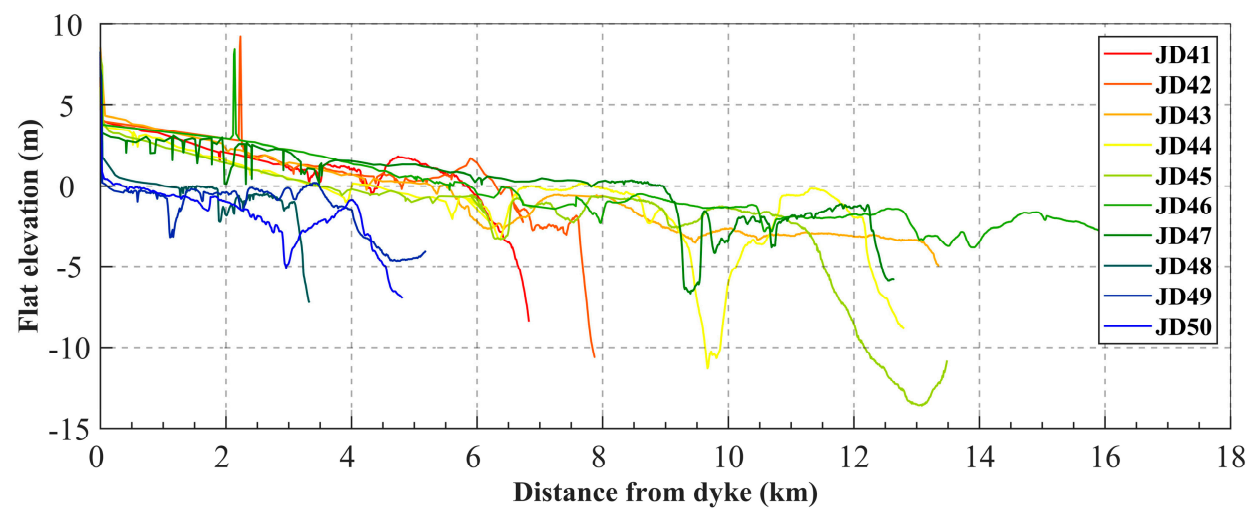

Figure 6. Measured bed elevation of the 50 profiles.

Thus, in this Baseline Method, for the profiles not affected (Figure 7 black dots) by the dykes or large tidal creeks, we calculate the beach slope from MHW to MLW beach contours; for the affected ones (Figure 7 black circles), we calculate their slopes using the approach introduced above. In this study, we used the Baseline Method to calculate each intertidal beach slope.
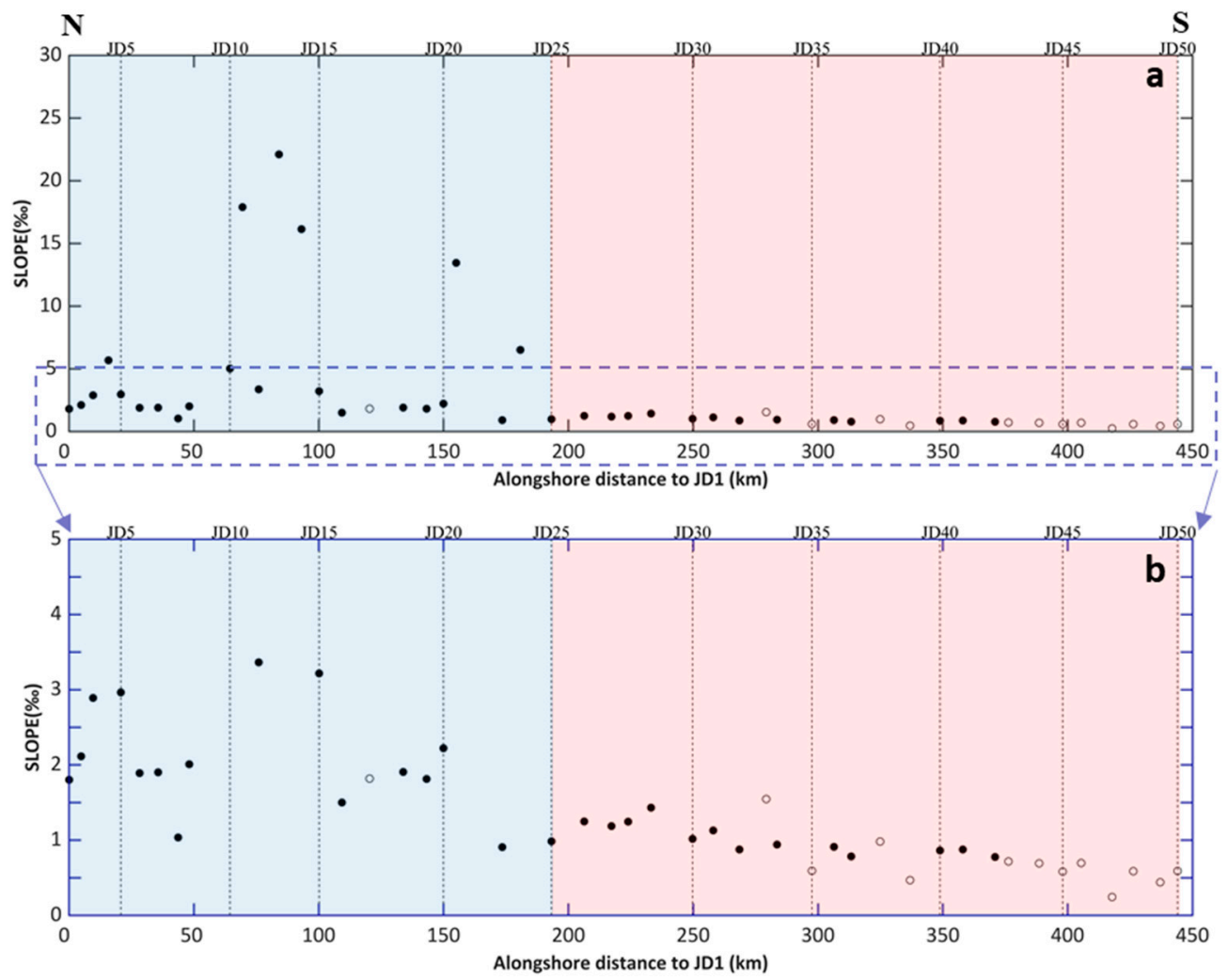

Figure 7. Calculated intertidal flat slopes of the 50 profiles based on Baseline Method (b) is a zoom in of the $0 \sim 5 \%$ part on (a). Black dots represent profiles not affected by dykes or large tidal creeks, and black circles are associated with profiles which are affected.

To ensure the consistency of the approach among different profiles, all sediment samples are included in the analysis, although same of them are located behind the new dykes. At each sample point, we take the mean sediment grain size $\left(M_{Z}\right.$ according to the [37] definitions as the representative grain size (see Equation (1)). Then we plotted the mean sediment grain size with reference to the cross-shore location to have a clear view of sediment grain size distribution pattern. Sediment types are classified according to the 
scheme proposed by [38], in which sand, silt and clay are defined as sediment with grain size of $-1 \sim 4 \Phi, 4 \sim 8 \Phi$ and $>8 \Phi$, respectively.

In order to further seek into the alongshore distribution pattern of sediment characteristics, more sediment characteristic parameters (sorting $\left(\sigma_{I}\right)$, and skewness $\left(S k_{I}\right)$ ) were calculated based on [37] definitions (see Equations (2) and (3)):

$$
\begin{gathered}
M_{Z}=\frac{\Phi_{16}+\Phi_{50}+\Phi_{84}}{3} \\
\sigma_{I}=\frac{\Phi_{84}-\Phi_{16}}{4}+\frac{\Phi_{95}-\Phi_{5}}{6.6} \\
S k_{I}=\frac{\Phi_{84}+\Phi_{16}-2 \Phi_{50}}{2\left(\Phi_{84}-\Phi_{16}\right)}+\frac{\Phi_{95}+\Phi_{5}-2 \Phi_{50}}{2\left(\Phi_{95}-\Phi_{5}\right)}
\end{gathered}
$$

where $\Phi_{84}, \Phi_{16}, \Phi_{50}, \Phi_{95}$, and $\Phi_{5}$ represent the phi values at $84,16,50,95,75,25$ and 5 percentiles in a cumulative frequency curve (i.e., horizontal axis: Sediment grain size in phi; vertical axis: Percentage of sediment coarser than a certain size by weight). The verbal classification scales for sorting and Skewness are shown in Tables 1 and 2, respectively.

Table 1. Classification scale for sorting.

\begin{tabular}{cc}
\hline$\sigma_{I}$ Values & Sorting Verbal Scale \\
\hline$<0.350$ & very well sorted \\
$0.35 \sim 0.500$ & well sorted \\
$0.5 \sim 0.710$ & moderately well sorted \\
$0.71 \sim 1.00$ & moderately sorted \\
$1.00 \sim 2.00$ & poorly sorted \\
$2.00 \sim 4.00$ & very poorly sorted \\
$>4.00$ & extremely poorly sorted \\
\hline
\end{tabular}

Table 2. Classification scale for skewness.

\begin{tabular}{ccc}
\hline $\boldsymbol{S} \boldsymbol{k}_{\boldsymbol{I}}$ Values & Skewness Verbal Scale & Graphically Skewed to \\
$-1.00 \sim-0.30$ & strongly negative skewed & strong coarse tail \\
$-0.30 \sim-0.10$ & negative skewed & coarse tail \\
$-0.10 \sim 0.10$ & near symmetrical & symmetrical \\
$0.10 \sim 0.30$ & positive skewed & fine tail \\
$0.30 \sim 1.00$ & strongly positive skewed & Strong fine tail \\
\hline
\end{tabular}

Because of continuous reclamations along the Jiangsu Coast, some dykes were newly built, which made it impossible to carry out the analysis of bed slope and sediment grain size from the same horizontal reference. Using Landsat 7 ETM satellite images, we checked the human activities processes on each profile from 1988 to 2008 and derived the time between measurement and nearest reclamation at each profile. The bed levels in front of and behind the newly built dykes were compared to find out whether these dykes influence intertidal beach evolution.

\section{Results}

\subsection{Cross-Shore Intertidal Beach Shape}

The measured 50 cross-shore profiles are shown in Figure 6 (note that the horizontal axis scales are different between the first three and the other two panels). As the measurements started from the top of old dykes, a sharp decrease in bed elevation in the seaward direction can be observed at the beginning of each profile. Some abnormal peaks can also be noticed on the upper part of the profiles; according to the investigation report [36], the large peaks are newly built dykes and small ones are abandoned stones and fences of small fishponds. Generally, the south part of Jiangsu Coast has wider and flatter tidal flats 
with a width that may exceed $10 \mathrm{~km}$. However, the southern profiles also tend to be more fluctuating, and that is because of the existence of shore-parallel tidal channels and creeks, especially in the RSRs region (see Figure 5).

Figure 7 depicts the intertidal flat slopes of the 50 cross-shore sections. Generally, cross-shore slope decreases from north to south along the Jiangsu Coast, see Figure $7 \mathrm{~b}$ for the $0-5 \%$ part. At the eroding north coast, intertidal flat slope is several times larger than on the accretionary south part. Furthermore, the slope distribution fluctuates a lot in the north part. JD9 has very small value, because the measurement took place near small estuary, where riverine supplied sediments can prevent severe erosion. The very large values (>15\% ) between JD10 and JD15 are because of the existence of rocky coastline. Apart from these local outliers, the slope decreases from north to south in the eroding north part. At the south part, the slope is basically below $1 \%$ and the southward flattening trend can be more apparent than it in the north part.

\subsection{Sediment Grain Size Distribution}

Mean grain size $\left(M_{Z}\right)$ averaged over sample points on the intertidal part of each profile are shown in Figure 8. The sediment grain size shows a notably southward coarsening pattern ( $\Phi$ value decreases) in the south part. In the north part, it shows much variability. A southward fining pattern can be clearly observed only in the small part from profile 20 to profile 25. Compared to the surrounding zone, the bed surface sediment on profile 20, at the top of AYRD, is quite coarse (Figure 8). This is understandable, as the top of the AYRD is under heaviest erosion.

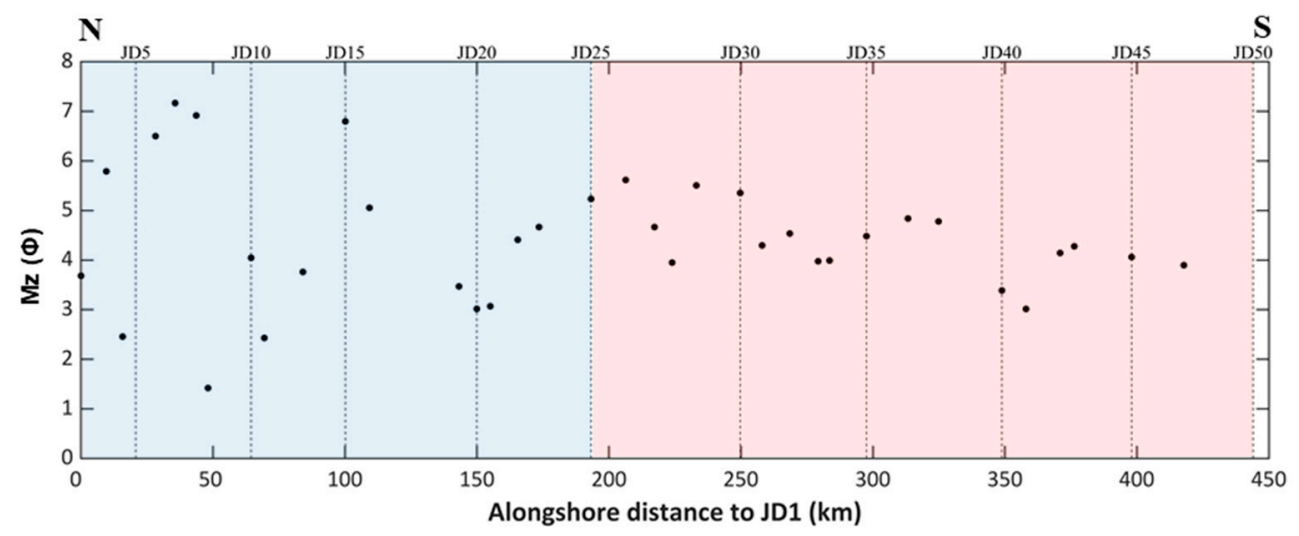

Figure 8. Averaged (through profile) bed surface mean sediment grain size of each profile.

Figure 9 shows the spatial (alongshore and cross-shore) variation of the sediment characteristic parameters. As can be seen in the figure, most sample points are located on the intertidal flats except only very few points in the south part (Figure 9 first panel).

In the cross-shore direction, the grain size generally decreases in the landwards direction. This is a common pattern for tide dominated coasts [21]. However, in the alongshore direction, we cannot directly tell if north part of Jiangsu Coast has finer sediment than the south part, because both dark red dots (very fine sediment) and dark blue dots (very coarse sediment) can be found. The sediment type in the north Jiangsu Coast can be sometimes sand dominant or clay dominant, while in the south part, it is basically silt dominant. As the Jiangsu coastal areas can be treated as a quasi-enclosed sediment system nowadays, the sedimentation in the south Jiangsu Coast partly comes from the eroded fine sediments in the north part. However, it is noted the extremely fine sediments are hardly found in the south part.

For most profiles, the bed surface sediment becomes from sand dominant to silt dominant landward (Figure 9 panel 4 6). Only in the very north zone (blue zone) the clay content can reach a relatively high proportion (note that the color bar limitation for clay proportion is from $0 \%$ to $40 \%$, not $100 \%$ ). In the south part, the sand proportion increases 
southward around MLW, and the clay proportion decreases southward around MHW. The silt content remains almost uniform.
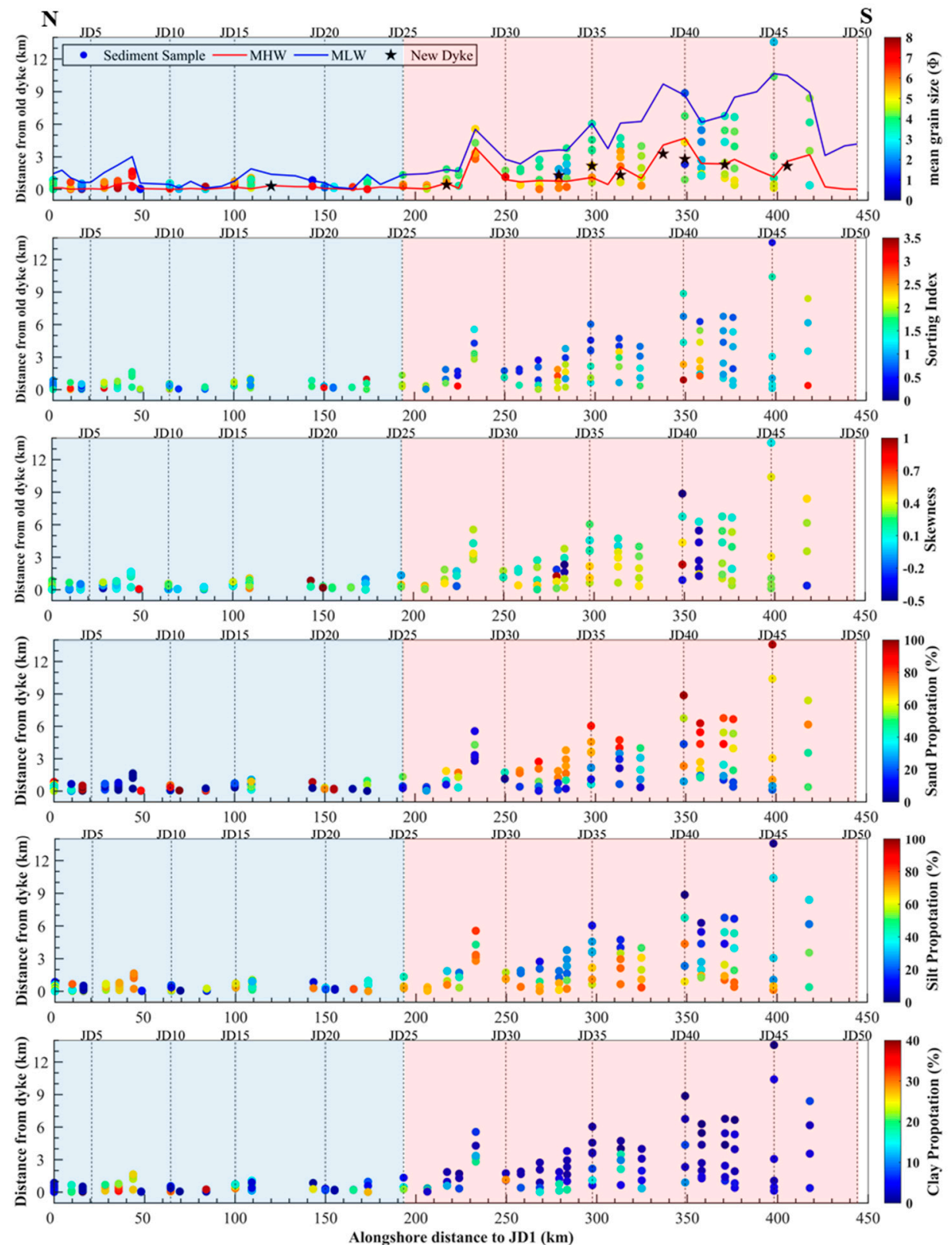

Figure 9. Bed surface sediment characteristic parameters distribution related to distance from old dyke (location of MHW, MLW, and new dykes are marked in the first panel).

The sorting is getting better seaward, which means the sediments in the sand dominant part are better sorted, while they are quite mixed in the shallower and silt dominant part. This sorting distribution is also consistent with the observation that in this tidedominated environment, the upper part of the intertidal beach is less dynamic than the lower part [39]. The Skewness distribution shows that the sediment is fine-skewed for most of the samples, and it becomes more fine-skewed landward. This indicates that the upper part of the intertidal flat tends to have excess fine materials, consistent with the landward fining pattern.

In the cross-shore direction of the Jiangsu Coast, sediment tends to be finer landward. This is opposite to wave-dominated sandy beaches, where the coarsest sediment is near shoreline. Comparing the alongshore intertidal beach slope variation and sediment grain 
size variation, an interesting phenomenon has been observed at the accretionary south part of the Jiangsu Coast. While tidal flat slopes are becoming milder towards the south, the corresponding bed surface sediment grain size is becoming coarser southward. This seems to be opposite to wave-dominated sandy beaches, where milder wave conditions tend to be associated with finer sediments. Another seemingly unexpected phenomenon is that sediments at some of the profiles in the eroding north part are much finer than in the accreting south. These seemingly unexpected phenomena are further discussed in the discussion section.

\subsection{Human Interventions}

The time difference between the profile measurement and the most recent reclamation at each location is shown in Figure 10. Recent reclamations mostly took place in the south part, where the construction time is very close to the measurement time. Earlier reclamations usually took place above the MHW, whereas more recent reclamations gradually extend to deeper areas (especially at the tidal flats shielded by the RSRs, see profile 33 and 35 in Figure 9 first panel and Figure 11). We need to compare the bed elevation in front of and behind these dykes to find out how dyke construction has affected the bed level changes.

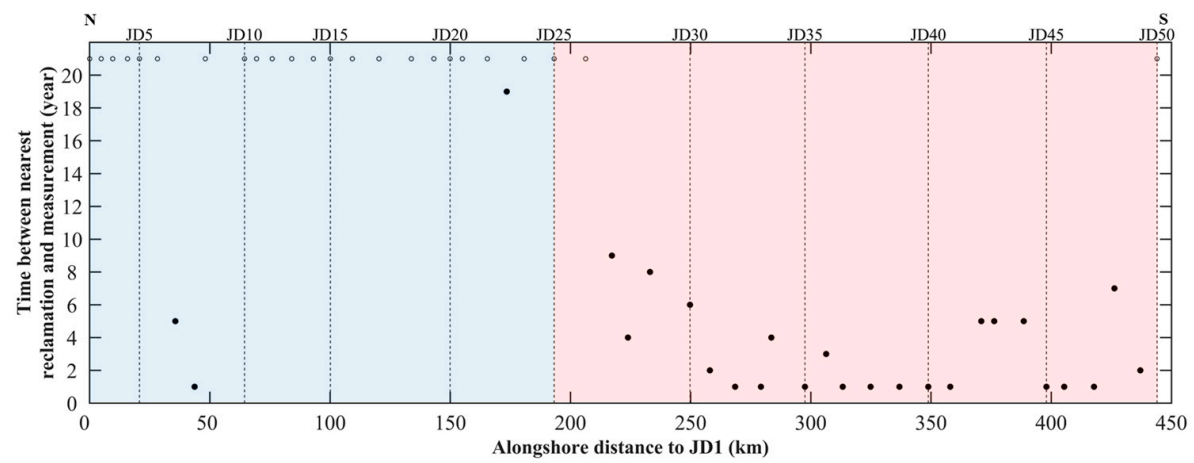

Figure 10. Time between measurement and nearest reclamation at each profile (circles means time larger than 20 years).
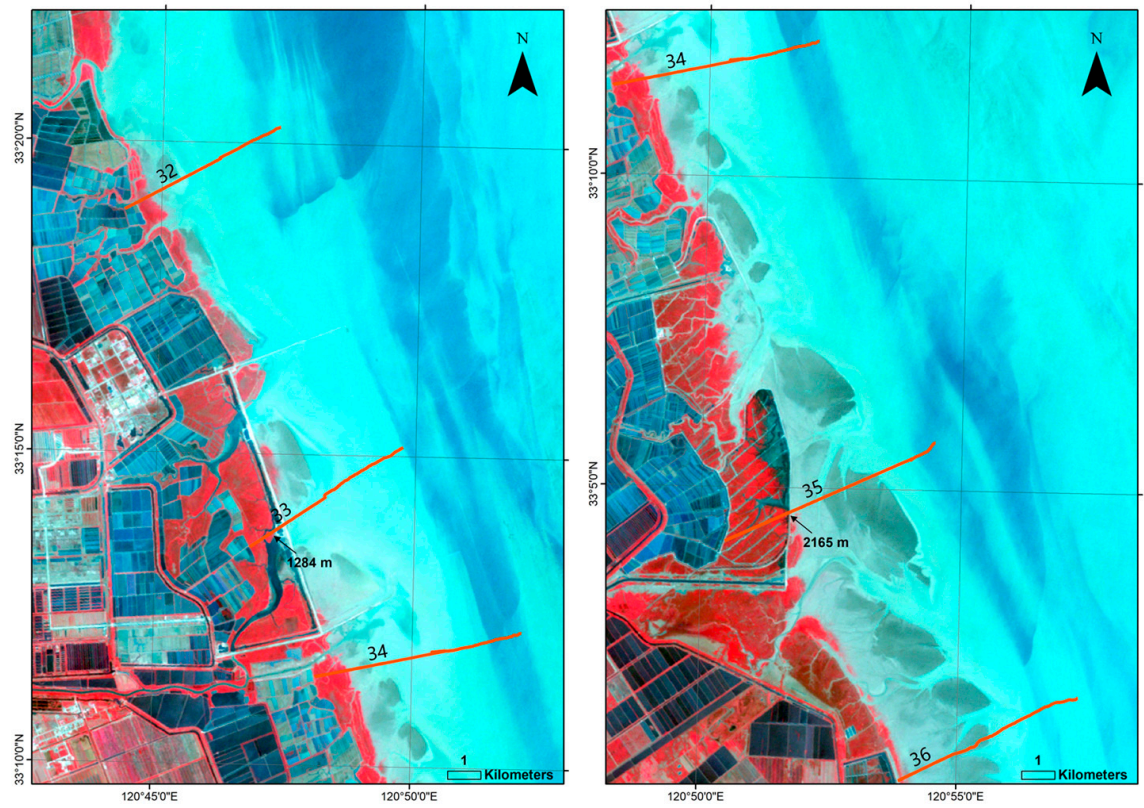

Figure 11. Satellite images of the JD 33 and 35 from Landsat 7 ETM on 5 July 2008 (arrows indicate the location of new dykes on each profile and distance to the old dykes). 
Figure 9 (first panel) shows that only for profiles JD17 (at the eroding part), JD33 and 35 (at the accreting part), dykes are located on the intertidal zone. Zooming in around the new dykes of these three profiles (Figure 6) we can easily compare the bed elevation in front of and behind these dykes (Figure 12). The bed elevations remain almost the same in front of and behind the dykes in JD33 and 35. At JD17, the dyke was built 20 years ago, so we can treat it as an old dyke, and the lower bed elevation in front of it suggests strong erosion.
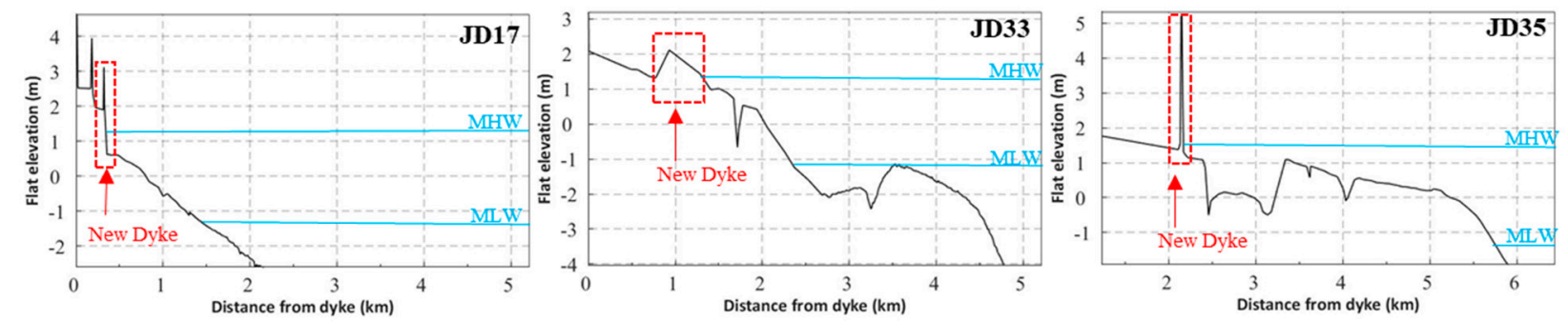

Figure 12. Zoom in on the bed elevation in front of and behind the newly built dykes (note that the scales of the three panels are not uniform).

In summary, we conclude that:

1. Intertidal beach slopes are larger in the eroding north part of the Jiangsu Coast than in the accreting south part. Apart from some outliers that relate to rocky parts of the coastline, beach slopes show a southward flattening trend in both the north and south part of the coastline, albeit more obvious in the accreting south part.

2. In the cross-shore direction, the bed surface sediment grain size decreases landward, and the sorting is getting better seaward. In the alongshore direction, the sediment grain size distribution pattern is more complex, with explicitly the following two features: In the eroding north part, both extremely fine sediment dominant profiles and coarse sands dominant profiles can be found. In the accreting south part, sediment grain size shows a southward increasing pattern.

3. Human interventions continuously took place along the Jiangsu Coast. The most recent dykes in the northern Jiangsu Coast were built more than 20 years before the time of measurement. While in the south part, new dykes were built more recently, most within one year time before the measurement.

\section{Discussion}

\subsection{Reliability of the Results}

The way we defined the beach slope cannot guarantee all results are calculated under the same reference, because at some profiles MHW is above the elevation of the dyke toe, while at some other profiles large alongshore direction tidal creeks could cut the profiles into separate parts. This was resolved through application of the Baseline Method; however, this could influence the alongshore intertidal beach slope distribution pattern we found. In order to check if slope definition boundaries influence the observed variation pattern, intertidal beach slopes were recalculated on the basis of different contour levels, namely from $-1 \mathrm{~m}$ to $1 \mathrm{~m}$ (Sensitivity scenario 1 ) and $-0.5 \mathrm{~m}$ to $0.5 \mathrm{~m}$ (Sensitivity scenario 2 ), respectively, as the mean sea level is around $0 \mathrm{~m}$. Sensitivity scenario 2 thus provides a zoom in with respect to scenario 1 . These two scenarios with narrowed vertical ranges can avoid the dykes and some of the tidal creeks influences.

Figure 13 shows the results of alongshore beach slope distribution calculated with different upper and lower boundaries. For most profiles, results are similar to each other, with only minor difference (less than 1\%) in magnitude. They all show a southward slope decreasing trend and this trend is more notable in the south part. With all these boundaries, the beach slope along the north part is quite fluctuating, because the beach 
type is variable in this part. However, there are still some profiles having large variations among these scenarios. Figure 14 indicates the standard deviation of the beach slopes calculated with three different boundaries. It is based on three data points only and serves as an indication to highlight variability in results. Apparently, for the north part more variability can be noticed. While in the south part, the variations are relatively small. Therefore, in the north part, the estimated beach slopes are more sensitive to the chosen upper and lower boundaries of the intertidal profile as used in the analysis. The above comparison result means the beach slope definition boundaries do have an impact on the detailed slope distribution, but do not change the key-findings on the beach slope southward flattering pattern.

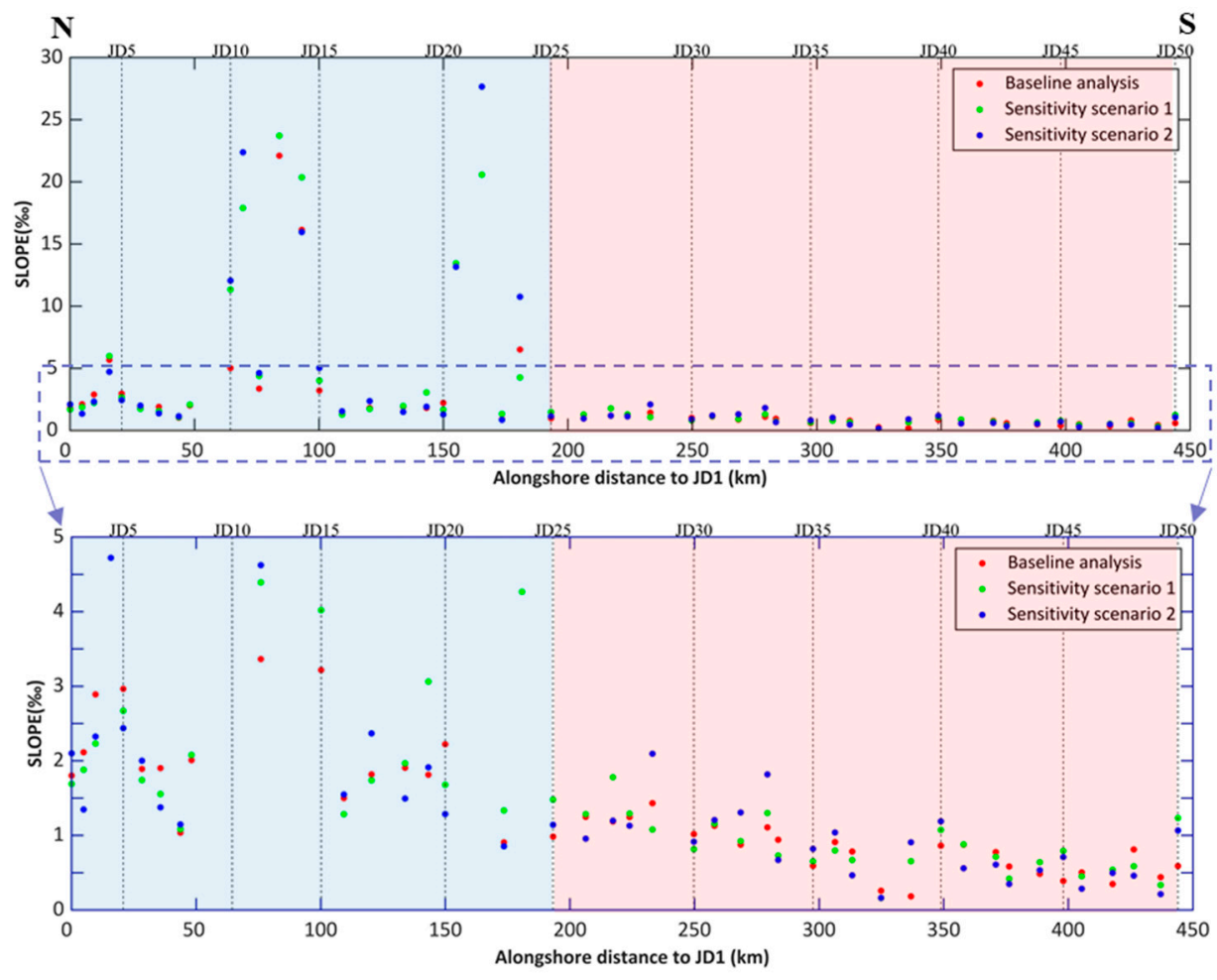

Figure 13. Intertidal beach slopes of the 50 profiles calculated with different boundaries.

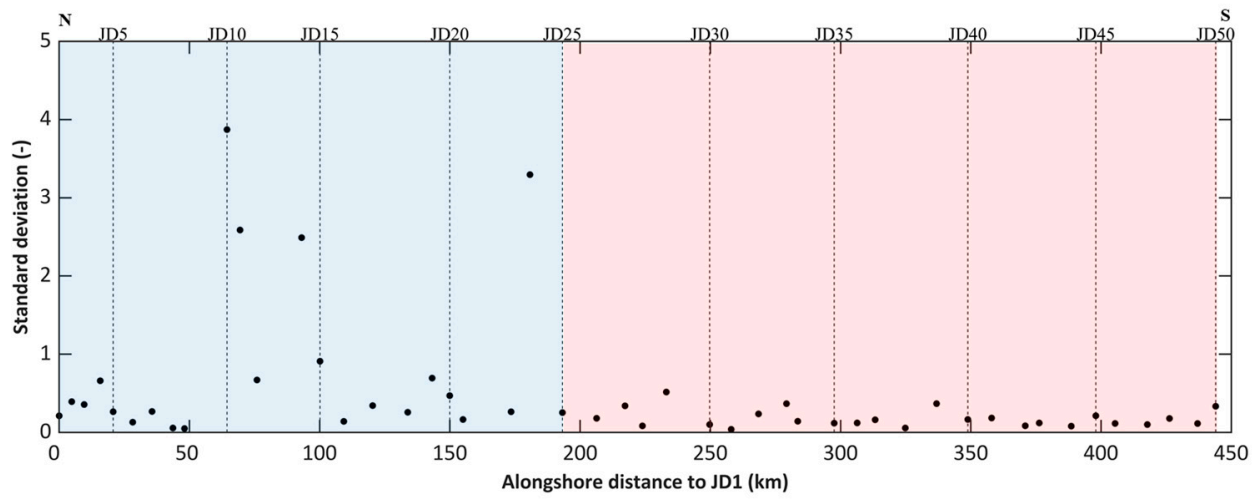

Figure 14. Standard deviation of three intertidal beach slopes calculated with different boundaries.

In Figure 15, the beach profiles were divided into two parts (divided at $0 \mathrm{~m}$, about the mean sea level) in order to see the profile shape (concave-up or convex-up). JD20 is located on the top of AYRD (see Figure 1c), which is under the greatest erosion. From JD20 to JD50, the beach profiles changes from concave-up to convex-up, which is consistent with shoreline condition (eroding profiles tend to be concave-up while accretionary ones tend to 
be convex-up). As the tidal range increases southward, the beach profile tends to be more convex-up towards the south. This pattern was also found at the tidal flats in South San Francisco Bay [40].

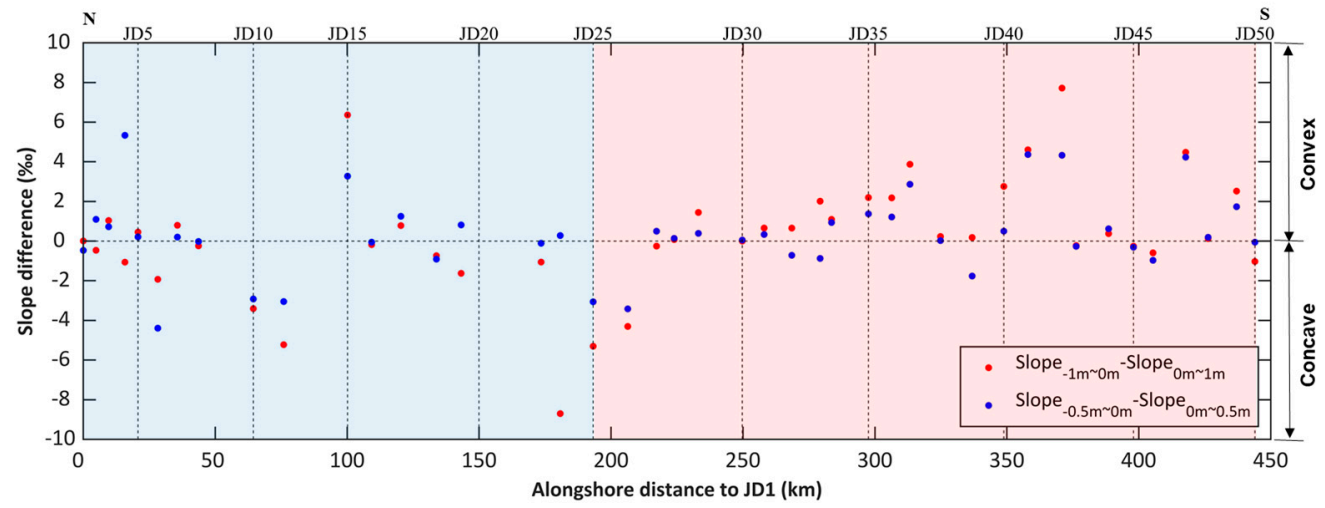

Figure 15. Upper and lower intertidal beach slope difference of the 50 profiles calculated with different boundaries.

From this sensitivity analysis, we conclude that the southward flattening beach slope pattern found in this study is not affected by the specific definitions used to derive beach slopes from the field data, nor from the quality of the data itself.

\subsection{Extremely Fine or Coarse Sediment in the North Coast}

In the north part, extremely fine (clay component dominant) or extremely coarse (sand component dominant) sediment are present (Figure 9). This fluctuating pattern can be explained by the occurrence of two erosion resistance mechanisms, namely self-weight consolidation and armoring of the beach surface.

Cohesive fine sediment is an important component of the silt-muddy tidal flat and its self-weight consolidation processes [18] play a significant role on the tidal flat morphological evolution [41]. Consolidation makes the bed material less erodible. Figure 9 shows that the grain size of fine sediment in the north Jiangsu Coast can be less than $8 \Phi$, which is in the range of clay. During the long-time formation of the AYRD, the cohesive sediments settled on the delta got enough time to get well consolidated and formed an erosion resistant layer. Thus, although the north Jiangsu Coast is under erosion, the eroding system ends up at the erosion resistant layer and the upper layer silts are transported southward. This erosion resistance due to consolidation effects has resulted in the presence of fine-sediment hotspots along the north Jiangsu Coast. This mechanism explains the seemingly unexpected phenomenon that sediments at some profiles in the eroding north part can be finer than in the accreting part of the coast.

When the profiles have sufficient coarse sediment available, armoring of the bed surface by suspension of the fines also becomes an important factor limiting erodibility. As it can be seen from Figure 9, the bed surface sediment can also be coarse at some profiles, which is the contribution of the sand armoring effect. When the clay content is quite little, the finer components are easier eroded than the coarse ones. Under normal hydrodynamic conditions, the silt components were taken away, and the sand components still remained on the bed, which make the bed surface sediment be coarser-hence more resistant against erosion.

These two erosion resistance mechanisms can explain why the sediments in the eroding north part can be extremely fine or coarse, depending on the local clay content. Additionally, it indicates that silt is the main components transported southward. 


\subsection{Alongshore Variation of Intertidal Beach Slope and Sediment Grain Size}

The development of the tidal flat along the Jiangsu Coast is facilitated by three most essential conditions, namely a low-energy environment, sufficient sediment supply and a medium to large tidal range [42,43]. In addition to the hydrodynamics and sediment sources, human interventions can also influence the beach evolution. These three factors are discussed in the following in order to explain the seemingly strange relation between the grain size and beach slope variations along the coast: southward coarsening and flattening.

\subsubsection{Hydrodynamics}

Tide force is the main driver influencing the sediment erosion and transport processes along the Jiangsu Coast. The tidal range is much larger in the south part than in the north (Figures $2 b$ and 3 ). Larger tidal range favors wider flats [44]. Tidal motion, especially the alongshore tidal current, is considered to be the main force causing sediment erosion and transport along the Jiangsu Coast. Ref. [45] found that in a wave-absence systems, bed profile and mud content on the upper flat are independent of the alongshore tidal current magnitude. In contrast, the strong alongshore currents can erode mud on the lower flat and promote landward sand transport from the subtidal area to the lower flat, forming a sandy flat. In-situ measurements near Jianggang showed that the mean flood current speed was about 1.4 times of the ebb current speed, and the mean suspended sediment concentration during floods was 1.25 times of that during ebbs $[20,46]$. Thus, in the south part, coarser sediments in the subtidal area provided by RSRs tends to be easier transported to the shoreline, and the landward transport process made the sediment on the whole profile coarser. This tide-induced mechanism explains why the southward coarsening pattern is more apparent in the accreting part (i.e., JD25 to JD50).

The wave height is generally lower than $1 \mathrm{~m}$ in the RSRs area [47], because the RSRs form a natural barrier for the shoreline, dissipating a large amount of wave energy. This provides the sheltered flats in the south part favorable conditions to develop to flatter beach profiles. On wave-dominated beaches, as waves are further dissipated towards the shoreline, the maximum dynamics are found near the shoreline and decrease to deeper water. Therefore, the coarsest sediments are found near the shoreline and the sorting is better near the shoreline as well $[48,49]$. At the Jiangsu Coast, these three patterns were observed to be opposite, which further indicates that this is a tide-dominated coastline and waves are of secondary importance.

\subsubsection{Sediment Sources}

Both in-situ measurements and model simulations proved that the major sediment source for the modern Jiangsu mudflat are the RSRs and AYRD [20,50,51]. The width of intertidal zone at equilibrium is positively related to sediment supply, which means higher sediment supply leads to wider and flatter tidal flats [52]. The southward beach flattening tendency coincides with the shoreline evolution state that the north part of the Jiangsu Coast is eroding while the south part is accreting (Figure 2c). This means that the north part is losing sediment forming a sediment source for the south part. The south part can receive sediment supply not only from the eroded north part but also from the outside RSRs. The large-scale sediment budget the Jiangsu Coast according to model simulations [34] shows that tidal flats south to Jianggang receive more sediment from the RSRs than from AYRD. Towards the south, the intertidal flat has thus more potential sediment supply and can become wider and flatter.

For the southward coarsening pattern, we consider different sediment sources would also be a main reason contributing to this. In order to further analyze sediment composition in different zones, we plotted the sand-silt-clay triangle (Figure 16). Usually, sediment from the same source tends to show a straight band in this triangle (with constant silt-clay ratio) [53]. For our case, samples at JD26-50 have a turning point around the silt content between $60 \sim 80 \%$. This indicates that the sediments in the south part come from different sources. The alongshore sediment mineralogical composition difference further proves that 
the sediments on the Jiangsu Coast are from different sources $[54,55]$. The sediments in the AYRD mainly came from the Yellow River, and sediments from the Paleo-Yangtze River contributed to the formation of the RSRs. Nowadays both the AYRD and RSRs supply sediments to the south Jiangsu tidal flat. The RSRs provided sediments are coarser than the AYRD provided ones. As the south part tends to receive more sediment from the RSRs, the bed surface sediment tends to be coarser.

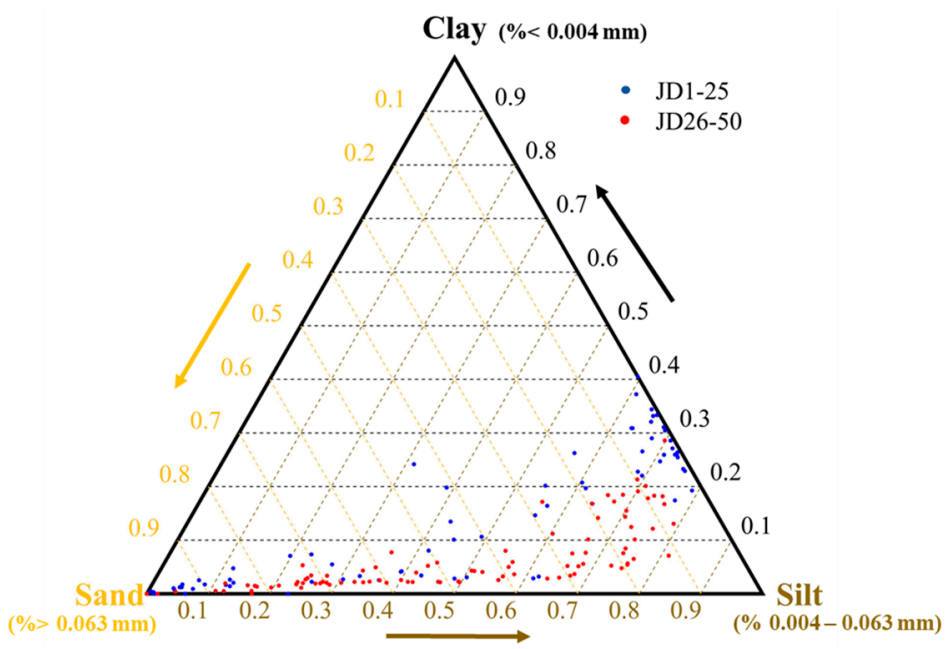

Figure 16. Sand-Silt-Clay triangle with two different color scatters, and colors representing different zones.

Studies on the beach profile and sediment grain size relationship for sandy beaches are all under the premise of equilibrium state [3-6,8], although equilibrium concept in coastal environment can be questioned [56]. Besides, this conclusion is driven based on a large dataset from different beaches, and we do not know if it also works for different profiles in the same beach. As the century-long erosion of AYRD and RSRs, their sediment supply is reducing [30], which means the evolution of the Jiangsu tidal flats has not been at an equilibrium state. As we only have one time large scale data, we cannot tell the temporal change of the relationship. Will this relationship change as the Jiangsu Coast further evolves and will sediment from different resources further redistribute? We still need numerical models to help us explore the change of this relationship as sediment supply reduces.

\subsubsection{Human Interventions}

Apart from natural processes, the beach slope and sediment grain size patterns we found could also be caused by human interventions.

According to previous studies (e.g., [57]), in an accretionary system affected by land reclamations, the intertidal flat will become narrower and steeper, and the surficial sediment tended to become finer on the mid-upper intertidal flat but coarser on the lower intertidal flat. However, the reclamations taking place in intertidal beaches are mostly located in the south part of the coast (see Figure 9 first panel). The observed southward flattening pattern is thus not in accordance with earlier findings by [57]. Meanwhile, we cannot find the accretion (see Figure 12) and finer sediment (Figure 9 first panel) near the dyke toe on the reclamation influenced profiles. The bed elevation in front of and behind the new dykes are almost the same (see Figure 12, JD 33 and 35). This is mainly because the time of this reclamation are so close to the measurement (Figure 10), so that morphology have not responded to the human interventions yet. From Figure 5 we can also see it clearly that the human interventions took place between 2007 and 2008, only several months before the measurement, which means there is limited time for the tidal flat to respond. It partly 
explains why we find that there is no obvious difference in bed elevation and sediment grain size between in front of and behind the dykes.

In conclusion, the influence of human interventions on the morphological and sedimentological characteristics of the Jiangsu Coast cannot be determined from this dataset, as it was collected too shortly after the implementation of large-scale land reclamation schemes. In order to check the influence of human interventions, more field survey needs to be carried on the temporal variation of tidal flat morphology.

\section{Conclusions}

Jiangsu Coast is a typical tide-dominant open coast with extended intertidal flats. This study investigates the intertidal beach slopes and surficial sediment grain size distribution pattern, using the high spatial-resolution field data from a large-scale coastal zone investigation. We analyzed the morphology and sediment characteristics of the Jiangsu Coast and found the following features:

1. Intertidal beach slopes are larger in the northern eroding part than in the accreting south part. A clear southward flattening pattern can be observed in the accreting south part.

2. The bed surface sediment grain size decreases landward in the cross-shore direction. In the alongshore direction, sediment grain size shows a southward increasing pattern in the south part.

3. Both extremely fine sediment dominant profiles and coarse sands dominant profiles can be found in the north part.

4. Human intervention continuously took place along the Jiangsu Coast. However, its influence on the morphological and sedimentological characteristics of the Jiangsu Coast cannot be determined from this one-time investigation dataset, as it was collected too shortly after the implementation of large-scale land reclamation schemes. More field surveys are needed to further study the tidal flat response to human interventions.

The extremely fine or coarse sediments in the north coast can be explained by two erosion resistance mechanisms, viz. consolidation effect and armoring effect. The southward flattening and coarsening pattern is due to the following factors: Flood-dominant current causing landward sediment transport, larger tidal range in the south part, sheltering effect of the RSRs and contribution of different sediment sources namely AYRD and RSRs. Waves play a minor role in this behavior. Whether the relationship between intertidal beach slope and bed surface sediment size will change when Jiangsu Coast evolution reaches an equilibrium state still remains to be solved.

Author Contributions: Conceptualization, research plan, Y.K., J.T., S.A., and Z.B.W.; supervision, J.T., S.A., and Z.B.W.; data collection and analysis, Y.K. and Z.Z.; writing-original draft preparation, Y.K.; writing-reviewing and editing, J.T., Z.Z., S.A., and Z.B.W. All authors discussed the results and contributed to the final manuscript. All authors have read and agreed to the published version of the manuscript.

Funding: The first author thanks the China Scholarship Council for providing the research grant. Jianfeng Tao is grateful to the funding from the National Natural Science Foundation of China (NO. 51620105005 and NO. 52071129) and the National Key Research and Development Program of China (NO. 2018YFC0407501).

Institutional Review Board Statement: Not applicable.

Informed Consent Statement: Not applicable.

Acknowledgments: Dineng Zhao from the Second Institute of Oceanography, China, is thanked for the kind assistance and help with the satellite images analysis.

Conflicts of Interest: The authors declare no conflict of interest. The funders had no role in the design of the study; in the collection, analyses, or interpretation of data; in the writing of the manuscript, or in the decision to publish the results. 


\section{References}

1. Muller, J.R.M.; Chan, Y.-C.; Piersma, T.; Chen, Y.-P.; Aarninkhof, S.G.J.; Hassell, C.J.; Tao, J.-F.; Gong, Z.; Wang, Z.B.; Van Maren, D.S. Building for nature: Preserving threatened bird habitat in port design. Water 2020, 12, 2134. [CrossRef]

2. van der Spek, A.J.; Elias, E.P. Half a century of morphological change in the Haringvliet and Grevelingen ebb-tidal deltas (SW Netherlands) -Impacts of large-scale engineering 1964-2015. Mar. Geol. 2021, 432, 106404. [CrossRef]

3. Dean, R.G. Equilibrium beach profiles: Characteristics and applications. J. Coast. Res. 1991, 7, 53-84.

4. Work, P.A.; Dean, R.G. Effect of varying sediment size on equilibrium beach profiles. In Coastal Sediments; ASCE: Reston, VA, USA, 1992; pp. 890-904.

5. Medina, R.; Losada, M.; Losada, I.; Vidal, C. Temporal and spatial relationship between sediment grain size and beach profile. Mar. Geol. 1994, 118, 195-206. [CrossRef]

6. Karunarathna, H.; Horrillo-Caraballo, J.; Kuriyama, Y.; Mase, H.; Ranasinghe, R.; Reeve, D.E. Linkages between sediment composition, wave climate and beach profile variability at multiple time-scales. Mar. Geol. 2016, 381, 194-208. [CrossRef]

7. Firoozfar, A.; Neshaei, M.A.L.; Dykes, A.P. Beach profiles and sediments, a case of Caspian Sea. Int. J. Mar. Sci. 2014, 4. [CrossRef]

8. Bujan, N.; Cox, R.; Masselink, G. From fine sand to boulders: Examining the relationship between beach-face slope and sediment size. Mar. Geol. 2019, 417, 106012. [CrossRef]

9. Lee, S.C.; Mehta, A.J. Problems in characterizing dynamics of mud shore profiles. J. Hydraul. Eng. 1997, 123, 351-361. [CrossRef]

10. Kirby, R. Practical implications of tidal flat shape. Cont. Shelf Res. 2000, 20, 1061-1077. [CrossRef]

11. Zhou, Z.; Coco, G.; van der Wegen, M.; Gong, Z.; Zhang, C.; Townend, I. Modelling sorting dy-namics of cohesive and non-cohesive sediments on intertidal flats under the effect of tides and wind waves. Cont. Shelf Res. 2015, 104, 76-91. [CrossRef]

12. Gong, Z.; Wang, Z.B.; Stive, M.J.F.; Zhang, C.; Chu, A. Process-Based Morphodynamic Modeling of a Schematized Mudflat Dominated by a Long-Shore Tidal Current at the Central Jiangsu Coast, China. J. Coast. Res. 2012, 285, 1381-1392. [CrossRef]

13. Mariotti, G.; Fagherazzi, S. Channels-tidal flat sediment exchange: The channel spillover mechanism. J. Geophys. Res. Ocean. 2012, 117, 1-18. [CrossRef]

14. Carling, P.; Williams, J.; Croudace, I.; Amos, C. Formation of mud ridge and runnels in the intertidal zone of the Severn Estuary, UK. Cont. Shelf Res. 2009, 29, 1913-1926. [CrossRef]

15. Kleinhans, M.G.; Schuurman, F.; Bakx, W.; Markies, H. Meandering channel dynamics in highly cohesive sediment on an intertidal mud flat in the Westerschelde estuary, the Netherlands. Geomorphology 2009, 105, 261-276. [CrossRef]

16. Soulsby, R.L. Dynamics of Marine Sands: A Manual for Practical Applications; Thomas Telford Publications: London, UK, 1997.

17. Van Rijn, L.C. Principles of Sediment Transport in Rivers, Estuaries and Coastal Seas, Part1; Aqua Publications: Amsterdam, The Netherlands, 1993; Volume 100.

18. Winterwerp, J.C.; van Kesteren, W.G. Introduction to the Physics of Cohesive Sediment in the Marine Environment; Elsevier Science Limited: Amsterdam, The Netherlands, 2004; Volume 56.

19. Coco, G.; Zhou, Z.; Van Maanen, B.; Olabarrieta, M.; Tinoco, R.; Townend, I. Morphodynamics of tidal networks: Advances and challenges. Mar. Geol. 2013, 346, 1-16. [CrossRef]

20. Ren, M.E. Comprehensive Investigation of the Coastal Zone and Tidal Land Resources of Jiangsu Province; Ocean Press: Beijing, China, 1986.

21. Wang, X.; Ke, X. Grain-size characteristics of the extant tidal flat sediments along the Jiangsu coast, China. Sediment. Geol. 1997, 112, 105-122. [CrossRef]

22. Ren, M.E. Modern Sedimentation in the Coastal and Nearshore Zones of China; Springer: New York, NY, USA, 1986.

23. Xu, F.; Tao, J.; Zhou, Z.; Coco, G.; Zhang, C. Mechanisms underlying the regional morphological differences between the northern and southern radial sand ridges along the Jiangsu Coast, China. Mar. Geol. 2016, 371, 1-17. [CrossRef]

24. Su, M.; Yao, P.; Wang, Z.B.; Zhang, C.K.; Stive, M.J.F. Exploratory morphodynamic modelling of the evolution of the Jiangsu Coast, China, since 1855: Contributions of old Yellow River-derived sediment. Mar. Geol. 2017, 390, 306-320. [CrossRef]

25. Gao, S. Modeling the preservation potential of tidal flat sedimentary records, Jiangsu coast, eastern China. Cont. Shelf Res. 2009, 29, 1927-1936. [CrossRef]

26. Li, C.X.; Zhang, J.Q.; Du Fan, D.; Deng, B. Holocene regression and the tidal radial sand ridge system formation in the Jiangsu coastal zone, east China. Mar. Geol. 2001, 173, 97-120. [CrossRef]

27. Zhang, R.S. Land-forming history of the Huanghe River delta and coastal plain of North Jiangsu. Acta Geogr. Sin. 1984, 39, 173-184.

28. Wang, Y.; Zhu, D.; You, K.; Pan, S.; Zhu, X.; Zou, X.; Zhang, Y. Evolution of radiative sand ridge field of the South Yellow Sea and its sedimentary characteristics. Sci. China Ser. D Earth Sci. 1999, 42, 97-112. [CrossRef]

29. Zhou, L.; Liu, J.; Saito, Y.; Zhang, Z.; Chu, H.; Hu, G. Coastal erosion as a major sediment supplier to continental shelves: Example from the abandoned Old Huanghe (Yellow River) delta. Cont. Shelf Res. 2014, 82, 43-59. [CrossRef]

30. Zhang, R.S.; Lu, L.Y.; Wang, Y.H. The mechanism and trend of coastal erosion of Jiangsu Province in China. Geogr. Res. 2002, 21, 469-478.

31. Milliman, J.D.; Huang-Ting, S.; Zuo-Sheng, Y.; Mead, R.H. Transport and deposition of river sediment in the Changjiang estuary and adjacent continental shelf. Cont. Shelf Res. 1985, 4, 37-45. [CrossRef]

32. Zhang, R.S. Suspended sediment transport processes on tidal mud flat in Jiangsu Province, China. Estuar. Coast. Shelf Sci. 1992, 35, 225-233. 
33. Xing, F.; Wang, Y.P.; Wang, H.V. Tidal hydrodynamics and fine-grained sediment transport on the radial sand ridge system in the southern Yellow Sea. Mar. Geol. 2012, 291, 192-210. [CrossRef]

34. Yao, P. Tidal and Sediment Dynamics in a Fine-Grained Coastal Region: A Case Study of the Jiangsu Coast. Ph.D. Thesis, Technology University of Delft, Delft, The Netherlands, 2016.

35. Wang, Y.; Zhang, Y.; Zou, X.; Zhu, D.; Piper, D. The sand ridge field of the South Yellow Sea: Origin by river-sea interaction. Mar. Geol. 2012, 291, 132-146. [CrossRef]

36. Zhang, C.K. The Comprehensive Survey and Evaluation Report on Coastal Zone of Jiangsu Province; Science Press: Beijing, China, 2012.

37. Folk, R.L.; Ward, W.C. Brazos River bar (Texas); a study in the significance of grain size parameters. J. Sediment. Res. 1957, 27, 3-26. [CrossRef]

38. Shepard, F.P. Nomenclature based on sand-silt-clay ratios. J. Sediment. Res. 1954, 24, 151-158. [CrossRef]

39. Le Hir, P.; Roberts, W.; Cazaillet, O.; Christie, M.; Bassoullet, P.; Bacher, C. Characterization of intertidal flat hydrodynamics. Cont. Shelf Res. 2000, 20, 1433-1459. [CrossRef]

40. Bearman, J.A.; Friedrichs, C.T.; Jaffe, B.E.; Foxgrover, A.C. Spatial trends in tidal flat shape and associated environmental parameters in South San Francisco Bay. J. Coast. Res. 2010, 262, 342-349. [CrossRef]

41. Whitehouse, R.; Soulsby, R.; Roberts, W.; Mitchener, H. Dynamics of Estuarine Muds; Thomas Telford Ltd.: London, UK, 2000.

42. Ren, M.; Zhang, R.; Yang, J. Sedimentation on tidal mud flat in Wanggang area, Jiangsu province, China. Mar. Sci. Bull. 1984, $3,41-54$.

43. Allen, J. Morphodynamics of Holocene salt marshes: A review sketch from the Atlantic and Southern North Sea coasts of Europe. Quat. Sci. Rev. 2000, 19, 1155-1231. [CrossRef]

44. Wang., Y.; Zhu, D. Tidal flats in China. In Oceanology of China Seas; Springer: Dordrecht, The Netherlands, $1994 ;$ pp. $445-456$.

45. Wang, Y.; Wang, Y.P.; Yu, Q.; Du, Z.; Wang, Z.B.; Gao, S. Sand-mud tidal flat morphodynamics influenced by alongshore tidal currents. J. Geophys. Res. Oceans 2019, 124, 3818-3836. [CrossRef]

46. Zhang, R.S. Characteristics of tidal current and sedimentation of suspended load on tidal mud flat in Jiangsu Province. Oceanol. Limnol. 1986, 17, 235-245.

47. Yang, B.; Feng, W.-B.; Zhang, Y. Wave characteristics at the south part of the radial sand ridges of the Southern Yellow Sea. China Ocean Eng. 2014, 28, 317-330. [CrossRef]

48. Prodger, S.; Russell, P.; Davidson, M. Grain-size distributions on high-energy sandy beaches and their relation to wave dissipation. Sedimentology 2017, 64, 1289-1302. [CrossRef]

49. Gunaratna, T.; Suzuki, T.; Yanagishima, S. Cross-shore grain size and sorting patterns for the bed profile variation at a dissipative beach: Hasaki Coast, Japan. Mar. Geol. 2019, 407, 111-120. [CrossRef]

50. Fu, M.; Zhu, D. The sediment sources of the offshore submarine sand ridge field of the coast of Jiangsu Province. J. Nanjing Univ. (Nat. Sci.) 1986, 22, 536-544.

51. Zhang, C.; Yang, Y.; Tao, J.; Chen, Y.; Yao, P.; Su, M. Suspended sediment fluxes in the radial sand ridge field of South Yellow Sea. J. Coast. Res. 2013, 65, 624-629. [CrossRef]

52. Liu, X.J.; Gao, S.; Wang, Y.P. Modeling profile shape evolution for accreting tidal flats composed of mud and sand: A case study of the central Jiangsu coast, China. Cont. Shelf Res. 2011, 31, 1750-1760. [CrossRef]

53. van Ledden, M.; van Kesteren, W.; Winterwerp, J. A conceptual framework for the erosion behaviour of sand-mud mixtures Cont. Shelf Res. 2004, 24, 1-11. [CrossRef]

54. Yang, S.; Li, C.; Jung, H.; Lee, H. Discrimination of geochemical compositions between the Changiiang and the Huanghe sediments and its application for the identification of sediment source in the Jiangsu coastal plain, China. Mar. Geol. 2002, 186, 229-241. [CrossRef]

55. Wang, L.; Hu, S.; Yu, G.; Ma, M.; Liao, M. Comparative study on magnetic minerals of tidal flat deposits from different sediment sources in Jiangsu coast, Eastern China. Stud. Geophys. et Geod. 2017, 61, 754-771. [CrossRef]

56. Zhou, Z.; Coco, G.; Townend, I.; Olabarrieta, M.; Van Der Wegen, M.; Gong, Z.; Zhang, C. Is "morphodynamic equilibrium" an oxymoron? Earth Sci. Rev. 2017, 165, 257-267. [CrossRef]

57. Wang, Y.P.; Gao, S.; Jia, J.; Thompson, C.E.L.; Gao, J.; Yang, Y. Sediment transport over an accretionary intertidal flat with influences of reclamation, Jiangsu Coast, China. Mar. Geol. 2012, 291, 147-161. [CrossRef] 